\title{
PROTEIN ENGINEERING SAMPLES THE FIELD
}

Protein Engineering. Edited by Dale L. Oxender and C. Fred Fox. Pp. 365. ISBN 0-8451-4300-X. $\$ 36.00$ (Alan R. Liss, Inc., New York, NY: 1987)

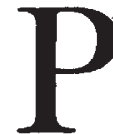

rotein engineering has emerged as a "field" as a consequence of the combined and complementary developments in molecular genetics and structural biophysics. Oxender and Fox offer the reader of this attractive text a "tutorial" on the methods and applications of protein engineering. The initial impetus for this particular gathering of papers was a UCLA Symposium held in April of 1985 at Keystone, Colorado; many of the thirty chapters in this book are derived from presentations at that meeting. Realizing, as did all who attended this landmark event, that a magic moment had been realized in the life of the burgeoning field of protein engineering, the editors chose to supplement the proceedings of the UCLA Symposium with some carefully chosen invited contributions. They thus have attempted, and in large part succeeded, to create a book that can instruct an uninitiated reader and provide a survey for those who are closer to the field but want a tour through its current activities.

Protein Engineering indeed captures the unique symbiosis of structural power available from. state-of-the-art $\mathrm{X}$-ray diffraction, nuclear magnetic resonance, and computational techniques and the nearly incredible choices in experimental design made possible by the new molecular biological tools. In fact, one author points out the problem created by the virtually limitless research opportunities that are now technically within reach: "... the important job is to ask the right question."

The volume is organized into four sections: I. Methods for Determining Protein Structure; II. Biological and Biochemical Methods in Protein Modification; III. Energetics and Protein Design; and IV. Purposely Modified Proteins and Their Properties. These are natural divisions of the material presented and provide a useful framework for selecting readings. Protein Engineering would serve as effective supplementary reading in courses on protein structure or protein engineering. For those who are active in related research areas, interest in the different topics discussed will undoubtedly vary. I found the last section to be fascinating: In one group are gathered most of the examples of intentional "engineering" of proteins, and the comparative assessment of the successes, failures, insights gained, and confusion created is enlightening. I was left with a clear sense that nature will not make it an easy task to dissect a protein and analyze its structural and functional properties through mutation.

The other side of a critical look at Protein Engineering is that it suffers from several flaws that are endemic to this type of book. The papers are necessarily out-of-date. A spot check reveals references through 1985 , with some in 1986 cited as "in press." This is a rapidly developing field and is certainly compromised somewhat by the vintage of the chapters. In general, the quality of the treatments and the breadth of subjects covered more than make up for a degree of datedness. On the other hand, the papers will seem superficial to any reader who is familiar with the area discussed. They resemble a seminar more than a scientific paper in their shortage of data and descriptive na- ture. But, Protein Engineering is claiming to be a "tutorial" after all, and readability is cited as one of its primary goals. The only other substantive criticism that might be raised about this book is that it is unfortunate the color pictures could not be incorporated into the text.

It is interesting to try to gauge the readership of this volume and to predict its impact. Scientists unfamiliar with current research in protein structure and the interrelationships with molecular biology will find it invaluable. Teachers will find it a useful reference to illustrate the things one can and hopes to do, and students will also learn the lesson that site-specific mutagenesis does not provide a panacea for all the poorly understood aspects of protein folding and function. Perhaps its most significant impact will be that it defines the field. New technological advances in molecular biology are leading to the creation of as many new words and terms as new areas of research. The appearance of this well-written and appealing book is appropriately timed to give it a central role in determining how the field of protein engineering will be viewed and defined. Fortunately, its authorship includes an impressive array of the practitioners of protein engineering-impressive both for their outstanding contributions and for their representation. Academic and industrial scientists number nearly equally among the authors. Like the book upon which Protein Engineering was modeled, Biophysical Science-A Study Program (1959), it will hold an important position in the scientific literature.

Lila M.Gierasch, Ph.D., is a professor of chemistry at the University of Delaware, Newark, DE.

\section{APPLYING COMPUTERS TO SEQUENCE ANALYSIS}

Nucleic Acid and Protein Sequence for coding and analyzing these data. Analysis: A Practical Approach. Edit- The molecular biologist is no longer ed by M. J. Bishop and C. J. Rawl- able to avoid the computer but must ings. Pp. 436. ISBN 1-85221-007-9. embrace it. Unfortunately for many, \$34.00. (IRL Press, Oxford, En- this new direction can be confusing gland: 1987).

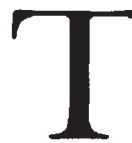
The explosive growth of powerful laboratory methods for analyzing nucleic acid sequences and derived sequences for proteins has required that computer methods be developed are employed and in many cases what some of the advantages and disadvantages are. For a number of the chapters, it is possible for the moderately sophisticated molecular biologist to decide on appropriate avenues for data processing and evaluation. In this review, I will briefly comment on the individual sections.

The introduction to computer hardware by M. J. Bishop initiates the volume and is a good analysis of hardware and software systems com- 